\title{
Relationship between depression and functional measures in overweight and obese persons with osteoarthritis of the knee
}

\author{
Daniel Possley, DO; ${ }^{1-2}$ Elly Budiman-Mak, MD; ${ }^{3-4}$ Susan O’Connell, MHA, RN; ${ }^{1}$ Christine Jelinek, MS; ${ }^{1}$ \\ Eileen G. Collins, PhD, RN $\mathbf{1}^{1,3,5 *}$ \\ ${ }^{1}$ Research \& Development Service, Edward Hines, Jr. Department of Veterans Affairs (VA) Hospital, Hines, IL; \\ ${ }^{2}$ Midwestern University, Chicago College of Osteopathic Medicine, Chicago, IL; ${ }^{3}$ Center for Management of Complex \\ Chronic Care, Edward Hines, Jr. VA Hospital, Hines, IL; ${ }^{4}$ Stritch School of Medicine, Loyola University of Chicago, \\ Chicago, IL; ${ }^{5}$ College of Nursing, University of Illinois at Chicago, Chicago, IL
}

\begin{abstract}
Depression is common in overweight and obese individuals with chronic illness. The purpose of this study was to determine the relationship between depression and functional status. Baseline data were used from 105 overweight/obese participants who enrolled in a clinical trial for overweight and obese adults with osteoarthritis of the knee. Forty-two percent of the sample was classified as depressed according to the Center for Epidemiologic Studies Depression Scale. A moderate relationship was seen between perceived physical function and physical performance in patients who were not depressed that did not exist in patients reporting depressive symptoms. In a stepwise regression analysis, poorer function (as measured by the Western Ontario and MacMaster Universities (Osteoarthritis Index) function subscale) and younger age accounted for 29 percent of the variance in depressive symptoms.
\end{abstract}

Clinical Trial Registration: ClinicalTrials.gov; Home-Based Exercise and Weight Control Program for Pain Control in Overweight Elderly with Osteoarthritis of the Knee, NCT00126737;

http://clinicaltrials.gov/ct2/show/

NCT00126737?term=home+based+exercise \&rank=4/.

Key words: 6-minute walk, depression, obese, osteoarthritis, osteoarthritis knee, overweight, physical activity, physical function, quality of life, walking impairment.

\section{INTRODUCTION}

Osteoarthritis (OA) is the most common form of arthritis, affecting an estimated 21 million people in the
United States in 1990 [1]. Depression is also highly prevalent in the United States, with 19 million people over the age of 18 years being affected by a depressive disorder in any given year [2]. In a recent longitudinal study of OA sufferers, 25.2 percent of 369 subjects met the criteria for depression [3-5].

The purpose of this study was to examine the relationship between depression and functional status of overweight and obese patients with OA of the knee. Our objectives were to (1) examine the prevalence of depressive symptoms in our sample; (2) examine the relationship between depressive symptoms, perceived physical function, and physical performance in overweight and obese adults with OA of the knee; and (3) determine what factors were associated with depressive symptoms. We hypothesized that (1) patients who reported more functional limitations would also report more depression, and

Abbreviations: $\mathrm{BMI}=$ body mass index, CES-D $=$ Center for Epidemiologic Studies Depression Scale, OA = osteoarthritis, SF-36 = 36-Item Short Form Health Survey, WIQ = Walking Impairment Questionnaire, WOMAC = Western Ontario and MacMaster Universities (Osteoarthritis Index).

* Address all correspondence to Eileen G. Collins, PhD, RN; Research Nurse Scientist, Research \& Development Service (151), Edward Hines, Jr. VA Hospital, Hines, IL 60141; 708202-3525; fax: 708-202-3906. Email: eileen.collins@va.gov DOI:10.1682/JRRD.2009.03.0024 
(2) lower reported function will account for significant variance in depressive symptoms for this sample.

\section{METHODS}

\section{Subject Selection}

After the study was approved by the Human Studies Subcommittee, we recruited patients with documented OA of the knee from the General Medicine and Arthritis clinics at a midwestern Department of Veterans Affairs (VA) Hospital and the surrounding community. Patients were identified with International Classification of Diseases-9th Revision codes 715.06 or 715.26 as a primary or secondary diagnosis. Identified patients were sent a letter of invitation. To be contacted by the staff, the patient needed to respond positively to the letter of invitation by returning a stamped, self-addressed information sheet. We then invited patients for an initial visit in the laboratory and obtained written informed consent.

\section{Inclusion Criteria}

Patients 50 years or older with documented OA of the knee were invited to participate. We documented OA of the knee as radiographic findings of tibiofemoral joint changes of Grades 2 to 3 using the Kellgren-Lawrence criteria. Additionally, we included patients if their knee pain was symptomatically defined as mild to severe pain for most days of the week for at least 6 months before entry and if they were functional Class I to III of the American Rheumatology Association functional capacity criteria, had a body mass index (BMI) between 27 and $40 \mathrm{~kg} / \mathrm{m}^{2}$, and were able to attend scheduled exercise and nutrition counseling sessions.

\section{Exclusion Criteria}

Patients were excluded if they had undergone arthroscopic surgery of the knee within the previous 3 months; had severe back, hip, or ankle pain that prevented them from walking; or had joint replacements in both knees.

\section{Description of Instruments}

\section{Center for Epidemiologic Studies Depression Scale}

The Center for Epidemiologic Studies Depression Scale (CES-D) is a 20-item measure designed to evaluate symptoms of depression in the community population [6]. A score of $\leq 16$ indicates that a person is not depressed, and a score of $>16$ indicates that a person is depressed. The CES-D has been shown to be reliable in general and patient populations, with internal consistency reported at 0.85 to 0.90 [6], and valid in patients with arthritis [7]. The CES-D has been successfully used in depression evaluation $[6,8]$ and in normal and psychiatric populations and correlates with the clinical diagnosis of depression [6].

\section{Western Ontario MacMaster}

The Western Ontario and MacMaster Universities (Osteoarthritis Index) (WOMAC) Likert 3.1 questionnaire is designed to measure functional loss and pain in persons with arthritis [9-10]. In the difficulty domain, the focus is measuring tasks related to activities of daily living. The WOMAC is a disease-specific measure of factors affecting quality of life in persons with OA. It contains 17 functional activity items, 5 pain-related items, and 2 stiffness items. The WOMAC is a valid and reliable instrument that has been used widely in a variety of clinical trials involving patients with OA of the knee [9,11-14].

\section{Walking Impairment Questionnaire}

The Walking Impairment Questionnaire (WIQ) is a self-administered, 14-item survey with three subscales: walking distance (7 items), walking speed (4 items), and stair-climbing ability (3 items). The WIQ assesses subjects' self-reported difficulty in walking a defined distance (half or less, one, two, or three city blocks); difficulty with which and how fast they are able to walk one block (walking one block slowly, at an average speed, or quickly or running or jogging one block); and difficulty climbing one, two, and three flights of stairs. Therefore, WIQ measures an individual's mobility and degree of difficulty in performing the tasks. All responses are scored on a 0 to 4 scale $(4=$ no difficulty, $3=$ slight difficulty, 2 = some difficulty, 1 = much difficulty, and $0=$ unable to do). The WIQ is scored by multiplying the degree of difficulty by a predefined number to represent distance (feet), speed (miles per hour) or stairs climbed (steps). The derived number is divided by the total possible score. A whole number percentage is then obtained by multiplying this value by 100 . The WIQ is primarily used in patients with peripheral arterial disease [15-16] but has also been validated in the cohort of patients in our study [17]. 


\section{Rand Short Form 36}

The 36-Item Short Form Health Survey (SF-36) was used to measure health-related quality of life. The SF-36, widely used, is a valid and reliable measure [18]. We used the Physical and Mental Composite scores in this analysis.

\section{3-Minute Stair Climb and Descend}

To assess stair-climbing ability, we asked subjects to complete a 3-minute stair climb and descend activity. At the signal to begin, subjects climbed four steps up, encountered a small landing at the top, and descended four steps down. When the subject reached the bottom of the four stairs, they turned $180^{\circ}$ and climbed and descended again [19]. For 3 minutes, the subject moved continuously, completing as many stairs as possible in the allotted time. Subjects were instructed that if they needed to stop before the 3 minutes were completed to simply stop where they were.

\section{6-Minute Walk}

The 6-minute walk is a test in which the subject walks for 6 minutes on level ground and the distance covered is measured [20]. The walk test was carried out in a $30.48 \mathrm{~m}$ level indoor straight corridor of the hospital. Subjects were instructed to cover as much ground as possible in 6 minutes. Patients were told to walk continuously if possible but that it would be permissible to slow down or stop if they felt it necessary to do so. The goal of the test was to have subjects adopt a self-selected walking speed such that at the end of 6 minutes, they would feel that they could not have walked any further. Subjects were encouraged and told when they had walked 1,3 , and 5 minutes.

\section{Statistical Analysis}

We used descriptive statistics (mean, standard deviation, range, and frequency) to characterize the sample and outcome measures. Pearson $r$ correlations examined relationships between outcome measures. Bivariate analysis compared the demographics and clinical characteristics of the cohort with/without depression. Hierarchical linear regression procedures examined predictors of depression and physical function. We used SPSS version 15.0 (Chicago, Illinois) for our analysis.

\section{RESULTS}

A total of 112 patients were enrolled in the study. Of these, 7 had missing data on the questionnaires or did not complete the questionnaires. Therefore, we used data from 105 patients in this analysis.

The sample consisted primarily (89\%) of older men (mean age \pm standard deviation $=67.5 \pm 8.4 \mathrm{yr}$ ) who reported having OA of the knee for an average of 10 years. The majority were Caucasian (89\%) and African American (6\%). They were $173.6 \pm 8.3 \mathrm{~cm}$ tall and weighed $103.5 \pm$ $19.5 \mathrm{~kg}$. They were obese with a BMI of $34.5 \pm 5.9 \mathrm{~kg} \cdot \mathrm{m}^{2}$. Sixty subjects (56\%) were classified as Kellgren-Lawrence Class 2 and forty-five (44\%) as Kellgren-Lawrence Class 3. On average, patients reported $2.3 \pm 2.0$ coexistent diseases with their OA of the knee.

Mean scores for the CES-D, WOMAC, WIQ, SF-36, 6-minute walk (distance), and 3-minute stair climb and descend activities (number of stairs) are listed in Table $\mathbf{1 .}$ The relationship between depression and major study variables such as age, duration of OA, number of coexisting comorbidities, WOMAC scores, and WIQ scores are presented in Table 2. Using the CES-D score, we classified patients as depressed $(>16)$ or not depressed $(\leq 16)$. Sixtyone patients (58\%) were classified as not depressed according to the CES-D, and forty-four (42\%) as depressed. Those

Table 1.

Descriptive information on selected variables in study of overweight patients with osteoarthritis of the knee.

\begin{tabular}{|c|c|c|}
\hline Measure & Mean \pm SD & Possible Range \\
\hline$\overline{\mathrm{CES}-\mathrm{D}}$ & $15.4 \pm 9.5$ & $0-60$ \\
\hline \multicolumn{3}{|l|}{ WOMAC } \\
\hline Pain Subscale & $12.3 \pm 3.5$ & $5-25$ \\
\hline Stiffness Subscale & $5.6 \pm 1.6$ & $2-10$ \\
\hline Function Subscale & $41.7 \pm 12.4$ & 17-85 \\
\hline \multicolumn{3}{|l|}{ Walking Impairment Questionnaire } \\
\hline Distance Subscale & $46.9 \pm 28.7$ & $0-100$ \\
\hline Speed Subscale & $39.5 \pm 22.7$ & $0-100$ \\
\hline Stair Climbing Subscale & $46.7 \pm 26.2$ & $0-100$ \\
\hline \multicolumn{3}{|l|}{ 36-Item Short Form Health Survey } \\
\hline Physical Composite Score & $36.9 \pm 8.3$ & $0-100$ \\
\hline Mental Composite Score & $50.1 \pm 10.9$ & $0-100$ \\
\hline 6-Minute Walk (distance [m]) & $443.8 \pm 102.7$ & 0-no upper limit \\
\hline $\begin{array}{l}\text { 3-Minute Stair Climb and Descend } \\
\text { (stairs [No.]) }\end{array}$ & $176.0 \pm 52.8$ & 0-no upper limit \\
\hline $\begin{array}{l}\text { CES-D = Center for Epidemiologic } \\
\text { deviation, WOMAC = Western Ont } \\
\text { arthritis Index). }\end{array}$ & $\mathrm{s} \mathrm{D}$ & le, SD = standard \\
\hline
\end{tabular}


Table 2.

Relationship between depression and selected variables.

\begin{tabular}{lcc}
\hline \multirow{2}{*}{ Variable } & \multicolumn{2}{c}{ CES-D } \\
\cline { 2 - 3 } & $\boldsymbol{r}$-Value & $\boldsymbol{p}$-Value \\
\hline Age (yr) & -0.35 & 0.001 \\
Duration of OA (yr) & 0.20 & 0.20 \\
Kellgren-Lawrence Classification & -0.06 & 0.45 \\
& (Kendall’s $\tau)$ & \\
Coexisting Diseases ( $n$ ) & 0.34 & $<0.001$ \\
BMI (kg/m ${ }^{2}$ ) & 0.13 & 0.10 \\
WOMAC Function & 0.54 & $<0.001$ \\
WOMAC Stiffness & 0.26 & 0.004 \\
WOMAC Pain & 0.43 & $<0.001$ \\
WIQ Total Score & -0.46 & $<0.001$ \\
SF-36 Physical Composite Score & -0.28 & 0.002 \\
6-Minute Walk (distance [m]) & -0.17 & 0.04 \\
3-Minute Stair Climb and Descend (stairs [No.]) & -0.14 & 0.07 \\
BMI = body mass index, CES-D = Center for Epidemiologic Studies Depres- \\
sion Scale, OA = osteoarthritis, SF-36 = 36-Item Short Form Health Survey, \\
WIQ = Walking Impairment Questionnaire, WOMAC = Western Ontario and \\
MacMaster Universities (Osteoarthritis Index). \\
\hline \hline
\end{tabular}

who were classified as depressed had more coexistent diseases, more impaired walking, had OA for a longer period of time, and more pain and stiffness and poorer function than those who were not classified as depressed (Table 3). We then examined the relationship between perceived physical function and measured physical performance among the depressed and nondepressed patients. Results are presented in Table 4. Stronger relationships were seen between perceived and measured physical ability in the nondepressed patients than in the depressed patients on the WOMAC.

We ran hierarchical, stepwise regression to determine predictors of depression in this sample. Using only variables with a significant correlation $(p=0.10)$ with depression, we determined a final compressed model. The final model included age as a demographic predictor and functional status as determined by the WOMAC function subscale. Perceived function predicted 24 percent of the variance while age predicted 5 percent of the variance. Together, the model predicted 29 percent of the variance of the depression scores (Table 5). Those patients who were younger with lower perceived function demonstrated higher rates of depression.

\section{DISCUSSION}

We report the following findings from this investigation. First, a higher percentage of patients screened positively for depression than has been reported by others.
Table 3.

Differences between depressed versus not depressed subjects.

\begin{tabular}{lcc}
\hline \multicolumn{1}{c}{ Variable } & $\begin{array}{c}\text { Not Depressed, } \\
\boldsymbol{n}=\mathbf{6 1} \\
\text { (Mean } \pm \text { SD) }\end{array}$ & $\begin{array}{c}\text { Depressed, } \\
\mathbf{n}=\mathbf{4 4} \\
\text { (Mean } \pm \text { SD) }\end{array}$ \\
\hline Age (yr) & $69.1 \pm 8.1$ & $65.9 \pm 8.6$ \\
Duration of OA (yr) & $7.7 \pm 4.9$ & $11.9 \pm 11.4$ \\
BMI (kg/m ${ }^{2}$ ) & $33.9 \pm 5.3$ & $34.8 \pm 6.5$ \\
\% Body Fat & $39.2 \pm 7.3$ & $40.2 \pm 8.2$ \\
Comorbid Diseases ( $n)$ & $1.8 \pm 1.6$ & $2.9 \pm 2.4$ \\
WOMAC Function & $20.8 \pm 9.7$ & $30.3 \pm 12.3$ \\
WOMAC Stiffness & $6.5 \pm 2.8$ & $8.1 \pm 3.6$ \\
WOMAC Pain & $6.3 \pm 2.9$ & $8.5 \pm 3.5$ \\
WIQ Total Score & $66.7 \pm 26.4$ & $48.9 \pm 28.0$ \\
SF-36 Physical Composite Score & $37.8 \pm 8.1$ & $36.0 \pm 8.3$ \\
Leg Strength (kg) & $43.0 \pm 15.3$ & $40.4 \pm 12.4$ \\
6-Minute Walk (distance [m]) & $453.3 \pm 103.8$ & $432.0 \pm 103.0$ \\
3-Minute Stair Climb and & $182.7 \pm 51.1$ & $169.3 \pm 53.6$ \\
\multicolumn{2}{c}{ Descend (stairs [No.]) } & \\
BMI = body mass index, OA = osteoarthritis, SD = standard deviation, SF-36 = \\
36-Item Short Form Health Survey, WIQ = Walking Impairment Questionnaire, \\
WOMAC = Western Ontario and MacMaster Universities (Osteoarthritis Index). \\
\hline \hline
\end{tabular}

Second, depression scores were related to perceived physical function and not as strongly to measured physical performance tasks. Lastly, lower function and younger age accounted for 29 percent of the variance in depressive symptoms.

Forty-two percent of our sample screened positively for depression with the CES-D. The mean value for the CES-D was 15 , compared with a score of 10 reported by other investigators [21-22]. Because our sample was primarily men, and depression is more commonly reported by women [23], this was an unexpected finding. Our sample did report higher levels of pain on the WOMAC pain subscale, which may account for higher reports of depression. Additionally, our sample was drawn from a primarily veteran population. It is well documented that veterans, in general, suffer from symptoms of depression more than nonveterans [24], and this may account for a higher incidence of depression in this sample.

Higher levels of depression in our sample were associated with reported decreased function, more knee stiffness, and more walking impairment than the nondepressed patients. Patients with depressive symptoms, even without a diagnosis of depressive disorder, have poor functioning and these symptoms become clinically meaningful. Thus, persons with knee OA may be more likely to report symptoms of depression and anxiety [25-26]. Sharma et al. demonstrated that the status of mental health (SF-36) 
Table 4.

Relationship ( $r$-value) between perceived and measured physical abilities in nondepressed and depressed patients.

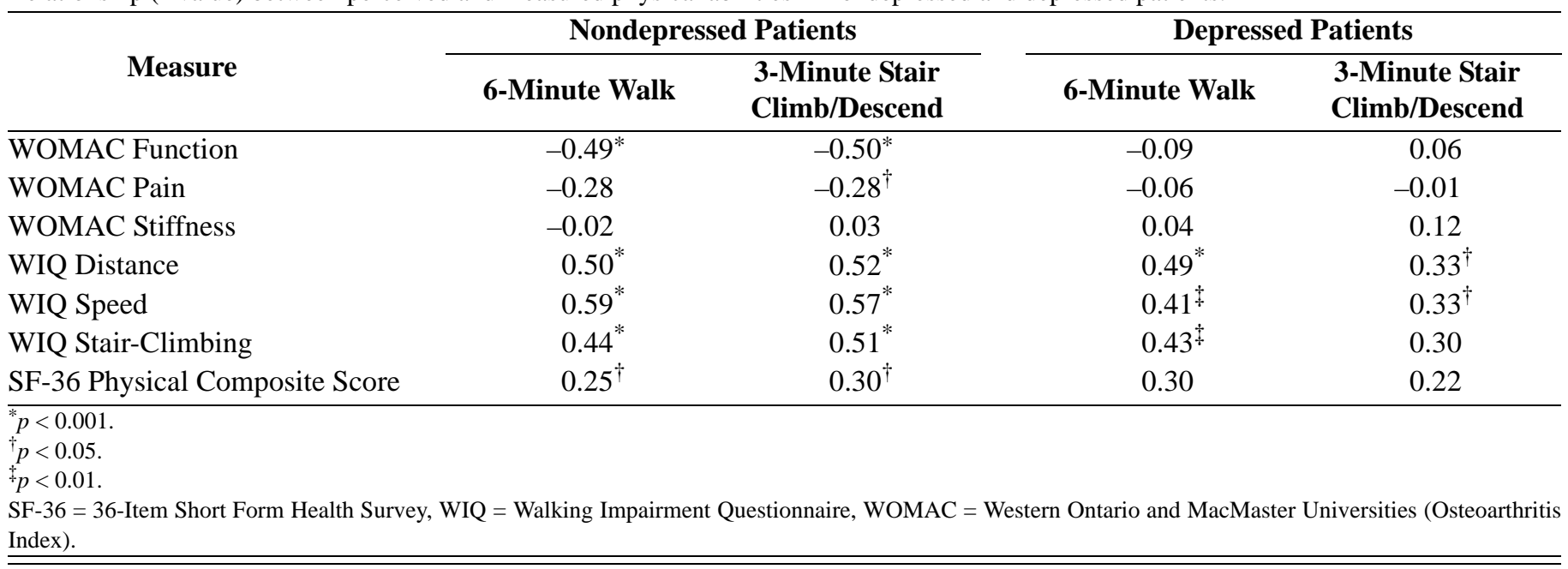

Table 5.

Regression analysis summary for variables predicting depression.

\begin{tabular}{lcccc}
\hline \multicolumn{1}{c}{ Predictor } & Adj $\boldsymbol{r}^{\mathbf{2}}$ & $\boldsymbol{R}^{\mathbf{2}}$ & $\boldsymbol{f}$ & $\boldsymbol{p}$-Value \\
\hline Function (WOMAC) & 0.24 & 0.24 & 22.9 & $<0.001$ \\
Age & 0.29 & 0.05 & 15.0 & $<0.001$
\end{tabular}

Adj = adjusted, WOMAC $=$ Western Ontario and MacMaster Universities (Osteoarthritis Index).

predicts physical function (WOMAC), because good mental health is a protector against poor function [27]. Creamer et al. did not find significant correlations between depression (CES-D) and disability scores (WOMAC) [28]. However, other investigators have reported moderately strong relationships between depression and function measured by the Sickness Impact Profile [29] and the Arthritis Impact Scale [30].

Interestingly, in both the nondepressed and depressed patients, moderate relationships were identified between the 6-minute walk distance and the number of stairs climbed and descended, as well as between the WIQ subscales and the SF-36 Physical Composite scores. Moderate relationships were also identified in the nondepressed patients for the WOMAC subscales; these relationships were not present, however, in the depressed patients. This unexpected finding is important because the WOMAC is commonly used in patients with knee OA. We postulate that in depressed patients, function may be so heavily influenced by depressive symptoms that the relationship between actual performance and ability may be lost. Alternatively, one could postulate that the questionnaires and performance indices are measuring different con- structs. When examining specific items on the WOMAC function subscale, one can surmise that depressed patients may have difficulty going shopping, getting dressed, or performing domestic duties, and these difficulties may have little to do with their physical ability to carry out these tasks. If this is the case, researchers and clinicians may need to consider the role of depression in selfreported physical function outcomes. In patients who are depressed, an instrument targeted at specific activities, such as the WIQ, may more accurately reflect the patient's physical ability.

Our regression model showed that physical function and age were associated with depression. Previous researchers reported that depression predicts self-reported physical function [3-4]; in our sample, self-reported poor physical function was a predictor of depression.

One limitation of our study may be that this cohort is predominantly male; the reported literature indicated that the severity and distribution of depression are different in males and females [17]. Therefore, analysis results about depression may not be generalized to females. Likewise, these results cannot determine the causal influence of depressive symptoms.

\section{CONCLUSIONS}

These data indicate that depressive symptoms in overweight and obese patients with OA of the knee are related to their self-reported physical function. Additionally, perceived function and younger age are determinants of 
depressive symptoms in overweight and obese persons with OA of the knee. More research is needed to determine whether our findings regarding the relationship between depression and perceived function and measured physical performance persist in larger, more diverse samples of patients with OA of the knee.

\section{ACKNOWLEDGMENTS}

\section{Author Contributions:}

Study concept and design: E. Budiman-Mak, E. G. Collins.

Acquisition of data: E. Budiman-Mak, S. O’Connell, C. Jelinek, E. G. Collins.

Analysis and interpretation of data: D. Possley, E. Budiman-Mak, E. G. Collins.

Drafting of manuscript: D. Possley, E. Budiman-Mak, S. O’Connell, C. Jelinik, E. G. Collins.

Critical revision of manuscript for important intellectual content:

D. Possley, E. Budiman-Mak, S. O’Connell, C. Jelinik, E. G. Collins.

Statistical analysis: E. Budiman-Mak, D. Possley, E. G. Collins.

Obtained funding: E. Budiman-Mak, E. G. Collins.

Administrative, technical, or material support: S. O’Connell.

Study supervision: E. Budiman-Mak, E. G. Collins.

Financial Disclosures: The authors have declared that no competing interests exist.

Funding/Support: This material was based on work supported by Department of Veterans Affairs Rehabilitation Research \& Development Service, grant E2-2362RA.

Participant Follow-Up: The authors plan to inform participants about the publication of this study.

\section{REFERENCES}

1. Lawrence RC, Helmick CG, Arnett FC, Deyo RA, Felson DT, Giannini EH, Heyse SP, Hirsch R, Hochberg MC, Hunder GG, Liang MH, Pillemer SR, Steen VD, Wolfe F. Estimates of the prevalence of arthritis and selected musculoskeletal disorders in the United States. Arthritis Rheum. 1998;41(5):778-99. [PMID: 9588729]

DOI:10.1002/1529-0131(199805)41:5<778::AIDART4>3.0.CO;2-V

2. Regier DA, Narrow WE, Rae DS, Manderscheid RW, Locke BZ, Goodwin FK. The de facto US mental and addictive disorders service system. Epidemiologic catchment area prospective 1-year prevalence rates of disorders and services. Arch Gen Psychiatry. 1993;50(2):8594.

[PMID: 8427558]

3. Parmelee PA, Harralson TL, Smith LA, Schumacher HR. Necessary and discretionary activities in knee osteoarthritis: Do they mediate the pain-depression relationship? Pain
Med. 2007;8(5):449-61. [PMID: 17661863]

DOI:10.1111/j.1526-4637.2007.00310.x

4. Maly MR, Costigan PA, Olney SJ. Determinants of self-report outcome measures in people with knee osteoarthritis. Arch Phys Med Rehabil. 2006;87(1):96-104. [PMID: 16401446] DOI:10.1016/j.apmr.2005.08.110

5. Patrick DL, Ramsey SD, Spencer AC, Kinne S, Belza B, Topolski TD. Economic evaluation of aquatic exercise for persons with osteoarthritis. Med Care. 2001;39(5):413-24. [PMID: 11317090] DOI:10.1097/00005650-200105000-00002

6. Radloff LS. The CES-D scale: A self-report depression scale for research in the general population. Appl Psychol Meas. 1977;1(3):385-401.

DOI:10.1177/014662167700100306

7. Blalock SJ, DeVellis RF, Brown GK, Wallston KA. Validity of the Center for Epidemiological Studies Depression Scale in arthritis populations. Arthritis Rheum. 1989;32(8): 991-97. [PMID: 2765012] DOI:10.1002/anr.1780320808

8. Diego MA, Field T, Hernandez-Reif M. CES-D depression scores are correlated with frontal EEG alpha asymmetry. Depress Anxiety. 2001;13(1):32-37. [PMID: 11233458]

DOI:10.1002/1520-6394(2001)13:1<32::AIDDA5>3.0.CO;2-G

9. Davis GM, Watson DJ, Bellamy N. Comparison of the responsiveness and relative effect size of the Western Ontario and MacMaster Universities Osteoarthritis Index and the short-form Medical Outcomes Study Survey in a randomized, clinical trial of osteoarthritis patients. Arthritis Care Res. 1999;12(3):172-79. [PMID: 10513507] DOI:10.1002/1529-0131(199906)12:3<172::AIDART4>3.0.CO;2-Y

10. Wolfe F, Kong SX. Rasch analysis of the Western Ontario MacMaster Questionnaire (WOMAC) in 2205 patients with osteoarthritis, rheumatoid arthritis, and fibromyalgia. Ann Rheum Dis. 1999;58(9):563-68. [PMID: 10460190] DOI:10.1136/ard.58.9.563

11. O’Reilly SC, Muir KR, Doherty M. Effectiveness of home exercise on pain and disability from osteoarthritis of the knee: A randomized controlled trial. Am Rheum Dis. 1999; 58(1):15-19. [PMID: 10343535$]$

DOI:10.1136/ard.58.1.15

12. Deyle GD, Henderson NE, Matekel RL, Ryder MG, Garber MB, Allison SC. Effectiveness of manual physical therapy and exercise in osteoarthritis of the knee. A randomized, controlled trial. Ann Intern Med. 2000;132(3): 173-81. [PMID: 10651597]

13. Baker KR, Nelson ME, Felson DT, Layne JE, Sarno R, Roubenoff $\mathrm{R}$. The efficacy of home based progressive strength training in older adults with knee osteoarthritis: A randomized 
controlled trial. J Rheumatol. 2001;28(7):1655-65.

[PMID: 11469475]

14. Martin K, Fontaine KR, Nicklas BJ, Dennis KE, Goldberg AP, Hockberg MC. Weight loss and exercise walking reduce pain and improve physical functioning in overweight postmenopausal women with knee osteoarthritis. J Clin Rheumatol. 2001;7(4):219-23. [PMID: 17039138] DOI:10.1097/00124743-200108000-00006

15. Collins EG, Edwin Langbein W, Orebaugh C, Bammert C, Hanson K, Reda D, Edwards LC, Littooy FN. Polestriding exercise and vitamin $\mathrm{E}$ for management of peripheral vascular disease. Med Sci Sports Exerc. 2003;35(3):384-93. [PMID: 12618567] DOI:10.1249/01.MSS.0000053658.82687.FF

16. Langbein WE, Collins EG, Orebaugh C, Maloney C, Williams KJ, Littooy FN, Edwards LC. Increasing exercise tolerance of persons limited by claudication pain using polestriding. J Vasc Surg. 2002;35(5):887-93.

[PMID: 12021703]

DOI:10.1067/mva.2002.123756

17. Collins E, O’Connell S, Jelinek C, Miskevics S, BudimanMak E. Evaluation of psychometric properties of Walking Impairment Questionnaire in overweight patients with osteoarthritis of knee. J Rehabil Res Dev. 2008;45(4):559-66. [PMID: 18712641]

DOI:10.1682/JRRD.2007.04.0053

18. Ware JE, Kosinski M, Gandek B. SF-36 Health Survey. Manual \& interpretation guide. Lincoln (RI): Quality Metric Incorporated; 2005.

19. Hagarty E, Skorodin MS, Langbein WE, Hultman CI, Jessen JA, Maki KC. Comparison of three different oxygen delivery systems during exercise in patients with hypoxemic chronic obstructive pulmonary disease. Am J Respir Crit Care Med. 1997;155(3):893-98. [PMID: 9117023]

20. Hamilton DM, Haennel RG. Validity and reliability of a 6-minute walk test in a cardiac rehabilitation population. J Cardiopulm Rehabil. 2000;20(3):156-64.

[PMID: 10860197] DOI:10.1097/00008483-200005000-00003

21. Maly MR, Costigan PA, Olney SJ. Contribution of psychosocial and mechanical variables to physical performance measures in knee osteoarthritis. Phys Ther. 2005;85(12): 1318-28. [PMID: 16305270]

22. Maly MR, Costigan PA, Olney SJ. Determinants of self-report outcome measures in people with knee osteoarthritis. Arch
Phys Med Rehabil. 2006;87(1):96-104. [PMID: 16401446$]$

DOI:10.1016/j.apmr.2005.08.110

23. Dunlop DD, Lyons JS, Manheim LM, Song J, Chang RW. Arthritis and heart disease as risk factors for major depression: The role of functional limitation. Med Care. 2004; 42(6):502-11. [PMID: 15167318] DOI:10.1097/01.mlr.0000127997.51128.81

24. Hankin CS, Spiro A 3rd, Miller DR, Kazis L. Mental disorders and mental health treatment among U.S. Department of Veterans Affairs outpatients: The Veterans Health Study. Am J Psychiatry. 1999;156(12):1924-30. [PMID: 10588406]

25. Wells KB, Stewart A, Hays RD, Burnam MA, Rogers W, Daniels M, Berry S, Greenfield S, Ware J. The functioning and well-being of depressed patients. Results from the Medical Outcomes Study. JAMA. 1989;262(7):914-19. [PMID: 2754791]

DOI:10.1001/jama.262.7.914

26. Badley EM. The effect of osteoarthritis on disability and health care use in Canada. J Rheumatol Suppl. 1995;43: 19-22. [PMID: 7752126]

27. Sharma L, Cahue S, Song J, Hayes K, Pai YC, Dunlop D. Physical functioning over three years in knee osteoarthritis: Role of psychosocial, local mechanical, and neuromuscular factors. Arthritis Rheum. 2003;48:3359-70.

[PMID: 14673987]

DOI:10.1002/art.11420

28. Creamer P, Lethbridge-Cejku M, Hochberg MC. Factors associated with functional impairment in symptomatic knee osteoarthritis. Rheumatology (Oxford). 2000;39(5): 490-96. [PMID: 10852978]

DOI:10.1093/rheumatology/39.5.490

29. Summers MN, Haley WE, Reveille JD, Alarcón GS. Radiographic assessment and psychologic variables as predictors of pain and functional impairment in osteoarthritis of the knee or hip. Arthritis Rheum. 1988;31(2):204-9.

[PMID: 3348824$]$

DOI:10.1002/art.1780310208

30. Salaffi F, Cavalieri F, Nolli M, Ferraccioli G. Analysis of disability in knee osteoarthritis. Relationship with age and psychological variables but not with radiographic score. J Rheumatol. 1991;18(10):1581-86. [PMID: 1765985]

Submitted for publication March 11, 2009. Accepted in revised form July 29, 2009. 
